\title{
Research in Rubber Manufacture
}

THE twelfth annual report of the Research Association of the British Rubber Manufacturers, presented at the annual meeting of the Association on Feb. 2, gives not only a succinct account of its varied activities but also a striking picture of the extent to which scientific research is serving the intellectual, technical, and material development of the rubber industry. Since the commencement of its career, the Association has contributed more than sixty papers to the scientific and technical Press, while nearly 25 per cent of the published matter in the Transactions of the Institution of the Rubber Industry from manufacturing sources originates from the Croydon laboratories. Apart from this, many confidential reports and circulars have been issued to members, and the scientific investigations carried out range from plasticity measurements on raw rubber, the comparison of Para, smoked sheet, and crepe, the properties of synthetic rubber or compounding ingredients such as litharge, accelerators and antioxidants, on the properties and testing of vulcanised rubber, to the numerous applications of vulcanised and hard rubber in tyres, cables and insulation materials, footwear, flooring, and proofings.

Joint investigations on cable insulation rubber have been carried out with the Admiralty, and on hard rubber and on a series of butadiene polymerisation products made by the I.G. Farbenindustrie A.-G. intended for use as insulation materials, with the British Electrical and Allied Industries Research Association. Testing apparatus has been devised which has simplified works' laboratory technique; and the cumulative value of the Association to the public, apart from the industry, is illustrated by the increased mileage of motor tyres, which as a result of research has increased from 2000 miles service in 1900 to 12,000 , with an estimated car-mile saving of at least $4 d$., or an approximate saving to the public of $£ 100,000,000$ on tyres of 1900 quality. An increase of $\mathbf{1 - 2}$ per cent in the life of boots, shoes, hot-water-bottles, etc., due to the use of antioxidants would represent a saving to the public far greater than the amount payable to the Research Association under the levy scheme.

In view of these results, it is somewhat disappointing to find that finance is still causing the Association a good deal of anxiety. In part this is due to the increased responsibilities thrown on the Association by the advance of scientific knowledge, and to the growing use of its services by members and subscribers, but the adverse and uncertain general economic conditions of trade have been a further factor. In addition, the reduction of the grant from the Department of Scientific and Industrial Research from $£ 2500$ to $£ 2000$ for 1932 as a measure of national economy has placed on the industry itself the onus of finding resources for any expansion in the scientific services provided by the Association. It is accordingly the more unfortunate that, although passing its second reading, the Rubber Industry Bill made no further progress, owing to the congestion of Parliamentary buisiness, and the expansion which the institution of the levy would make possible is still deferred.

Apart from its strictly scientific work, the Association participated in the successful negotiations between a committee representative of chemical interests generally and the British Engineering Standards Association which resulted in the formation of the British Standards Institution, covering the whole industrial field. The negotiations issued in a scheme providing for an organisation divided into four main divisions dealing with building, engineering, chemical, and textile interests, the proposals thus representing the fulfilment of one of the recommendations of the Imperial Conference dealing with co-ordination of standardisation within the Empire. On the Chemical Division Council the interests of the rubber industry are represented by the India-Rubber Manufacturers' Association, but the matter of standardisation is one of prime importance to the Research Association and, during the year, preliminary consideration has been given to the internal organisation of the rubber industry for the formulation of specifications for manufactured rubber goods, and the Association has co-operated during 1931 in the preparation or revision of British standard specifications for moulded insulating material for general electrical purposes, rubber tubing for use with petrol, benzol, and paraffin ; oil-resisting rubber tubing, rubber-jointing material, benzol and rubber belting.

Since there are no rubber organisations in the Dominions in any way analogous to the Research Association, apart from those in Ceylon and Malaya, the question of Imperial co-ordination in research scarcely arises in the rubber industry, but visits from representatives of the National Research Council of Canada and the Australian Council for Scientific and Industrial Research already afford a basis for some effective liaison when the systematic study of the problems of rubber manufacture is taken up in the Dominion or the Commonwealth. Close relations have been maintained between the Research Association and the Rubber Institute of Malaya, and a number of technical questions, such as the suitability of airdried sheet for manufacturing purposes, the concentration and extraction of latex serum in bulk, latex emulsification problems, have been discussed between the two organisations. In addition, although with the imposition of a small cess upon rubber exports for the maintenance of the Ceylon rubber scheme, financial responsibility passed from London to Ceylon, by joint arrangement between the organisations in Ceylon and Malaya a scheme has been evolved for transfer of control to a Joint Advisory Council, thus securing continuance of the scientific investigations of the properties of the raw material and close cooperation between the producer and the manufacturer.

Co-operation with the Rubber Growers' Association has also been established, not only in publicity work on behalf of the industry, but also in the investigation of difficulties holding up the utilisation of rubber for various purposes, and the study of promising potential applications. Among such problems may be mentioned the utilisation of latex-oil emulsions as lubricants, the acoustic properties of rubber flooring for cinemas, the increasing of the resistance of rubber to oils, while such questions as the destruction of rubber by white ants, rubber goods for tropical railways, resistance of coloured rubber paving to light and weather, have been the subject of joint discussion. Co-operation in the study of problems confronting the utilisation of rubber has, however, by no means been confined to the Rubber Growers' Association. Investigations on ebonite have been carried on jointly with the British Electrical and Allied Industries Research Association, in which the Ceylon rubber research scheme and representatives of Government departments have participated. The War Office, India Office, Air Ministry, and Post Office are all represented on the Association's Tyre Research Committee, and co-operation with the motor industry and the British 
Boot and Shoe and Allied Trades Research Association on problems relating to the manufacture and utilisation of rubber will undoubtedly develop.

An important feature of the work of the Association is its library and information bureau, which serve the growing needs of all connected with the industry for a source of information and advice over a wide range of subjects. Without the regular issue of the monthly summary of current literature it would be difficult for the industry to keep itself abreast of all the latest developments ; and when to this invaluable intelligence service there is added the issue of periodical circulars summarising the available knowledge on many scientific, technical, and economic subjects and the satisfying of an ever-growing number of inquiries (amounting to 690 in 1931 alone) covering all phases of the rubber industry, it can safely be asserted that the Research Association is rendering to the British industry services that are unsurpassed by the similar associations in Germany and Holland. In addition, a centralised organisation is able to carry out work of this kind much more thoroughly and efficiently than any one firm alone could hope to do, and avoids all the overlapping and duplication of effort which would occur if individual firms maintained their own organisations.

Already the number of cards in the index main. tained by the Association amounts to well over 125,000, and the subject cards alone are increasing by about 14,000 a year. These statistics, however, give little idea of the magnitude of the work involved in cross indexing, and in the course of the work the library and information bureau has evolved its own system of classifying scientific, technical, and commercial information on rubber, based on a generalised decimal notation, although the International Brussels system was rejected on account of serious difficulties it offers in use for rubber information. The value of the work of this section of the Association is further attested by the recognition of the library in 1930 by the Carnegie Trust as an outlier of the National Central Library. The generous grant made in accordance with that recognition has made it possible to expand considerably the library collection, and thus to im. prove further the utility of what is already a fully representative collection of all modern publications and particularly in regard to trade literature.

The above brief outline of the activities of the Association taken from the annual report gives some indication of the many services which the Research Association is rendering to the rubber industry, and illustrates the way in which that research reacts to the direct benefit of the public, as well as the tendency towards co-operative research between different branches of industry. One of the most surprising things in the report is the smallness of the staff with which this extensive and important work is being carried out. When we consider that as yet relatively little is known regarding the nature of rubber or the changes which occur during vulcanisation, apart altogether from the many problems presented by the utilisation of rubber, it is clear that the expansion in the work of the Association, and particularly the extension of systematic fundamental research which is anticipated as a result of the Rubber Industry Bill passing into law, should be of the utmost value and importance to the industry. Its practice cannot but be imperfect when the mechanism of the essential process is incompletely understood. The future of the rubber industry depends upon the wise, continuous, and adequate prosecution and application of scientific research, and the praiseworthy work already carried out by the Research Association indicates the possibilities when the industry as a whole devotes to the support of co-operative research the energy and financial support which it imperatively demands.

\section{Uses of Empire Timbers*}

TYNDER the auspices of the Forest Products Research Board of the Department of Scientific and Industrial Research, inquiries are being carried out into the possible uses of Empire timbers. The results of the first year's investigations are given in the annual Report of the Board before us. Under the auspices of the Empire Timber Committee the work was started late in 1929, further facilities for the contemplated research becoming available by the end of last year.

Tests have been undertaken with East African camphor wood from Kenya for cabinet making; walnut and sapeli woods from Nigeria, both for cabinet making; and Meranti tombaga and Keruing timbers from the Federated Malay States, which might displace some of the Philippine timbers on the London market, provided they can be imported at competitive prices. New Zealand silver beech is to be tested for furniture wood at High Wycombe and in the making of rifle stocks at the Small Arms Factory at Enfield. Another subject reported upon is the investigations into the creosoting of British Columbian Douglas fir, since this timber might prove a considerable asset for railway sleepers. So far, Douglas fir timber has proved less easy to creosote than Baltic fir. By adopting the Canadian and American method of what is known as 'incising' over the sleepers, it was found possible to inject as

* Department of Scientific and Industrial Research. Report of the Forest Products Research Board ; with the Report of the Director of
Forest Products Research for the Year 1930 . Pp. vii $+52+10$ plates. (London: H.M. Stationery Office, 1932.) 48. net.

No. 3262, Vor. 129] much creosote into them as the Baltic species will absorb.

The writers of the report comment upon the increased interest of the public in Empire timbers, for use in both Government and private buildings. But the opinion is stressed that the joint work of the Department and the Empire Marketing Board is not by itself sufficient to cover the necessities of achieving a general development and national use of Empire timbers. Unless production and marketing are closely co-ordinated with research, the work of the Board will be impaired. Apart from measures to be taken by the timber trade, it is stated that there is a lack of adequate official machinery for dealing with difficulties in the producing areas; more especially in certain of the tropical regions.

The difficulties, it is urged, could be largely overcome by comprehensive botanical and economic surveys of our forest resources, involving some enlargement of the facilities at the disposal of the Imperial Forestry Institute and the forest services, and by closer liaison and personal touch with the interests concerned in the country of origin. The suggestion of the enlargement of the facilities at the disposal of the forest services is timely at a moment when most of these services are being cut down owing to financial stringency.

The efforts of the departments responsible for the admirable work described in the report here dealt with require the careful consideration of the authorities responsible for forest administration in the various Colonies. 